Набиуллина Карина Рашидовна

кандидат экономических наук,

доцент кафедры градостроительства

и планировки сельских населенных мест

Казанского государственного

архитектурно-строительного университета

\section{ФАКТОР КУЛЬТУРНЫХ ТРАДИЦИЙ, ИНТЕЛЛЕКТУАЛЬНОГО И ИНФОРМАЦИОННОГО РЕСУРСОВ В УПРАВЛЕНИИ ИННОВАЦИЯМИ В ГРАДОСТРОИТЕЛЬНОМ РАЗВИТИИ}

\section{Аннотация:}

Вектор принимаемых решений в градостроительстве возникает под воздействием культурных предпочтений разных групп населения, тренда градостроительной политики, действующей проектной градостроительной и нормативной документации. Серьезный отпечаток на систему муниципального менеджмента и управления инновациями накладывает проблема "кадрового голода» - недостатка высокопрофессиональных специалистов почти во всех секторах управления городским развитием. Для сглаживания этого фактора эффективны модели управления, демонстрирующие "связку" уполномоченных органов муниципального управления с городскими активистами, бизнесструктурами, профессиональными консалтинговыми бюро или общественными организациями, m. е. добавочным «подключенным интеллектом». Велика роль местных средств массовой информации, которые информируют население о программах развития территории, предопределяют направления деловой активности, формируют отношение граждан к градостроительным инициативам муниципального управления, а также получают обратную связь - мнение жителей о предстоящих изменениях. Таким образом, при управлении инновациями в градостроительном развитии местности большое значение имеют сформированные культурные традиции, интеллектуальный и информационный ресурсы.

Ключевые слова:

управленческие инновации, градостроительное развитие, развитие территории, муниципальное управление.
Nabiullina Karina Rashidovna

PhD in Economics, Assistant Professor, Department of Urban and Country Planning, Kazan State University of Architecture and Engineering

FACTOR OF CULTURAL TRADITIONS, INTELLECTUAL AND INFORMATIONAL RESOURCES IN INNOVATION MANAGEMENT IN URBAN DEVELOPMENT

The decisions on urban planning are made under the influence of the cultural preferences of different groups of population, the trends in urban planning policy, the current project urban planning documents and standards. The problem of personnel gap, i.e. the lack of highly experienced experts in almost all sectors of urban development, has a serious impact on the system of municipal and innovation management. To balance this factor, it is effective to apply the management models demonstrating the connection between municipal governing authorities and urban activists, business entities, professional consulting bureau or public organizations that are an additional "connected intelligence". The role of the local media is important; they inform the population about the spatial development programs, predetermine the business lines, form the attitude of the citizens towards the urban planning initiatives of the municipal government. Besides, they get feedback, the opinion of the population about the forthcoming urban development changes. Thus, when managing innovations with regard to urban spatial development, the established cultural traditions, intellectual and informational resources play an important role.

Keywords: management innovations, urban development, spatial development, municipal management.

Культурные традиции сегодня выступают регулятором и ограничителем инновационных решений и преобразований в структуре управления градостроительным развитием. Объект и субъект управления неразрывно связаны в процессе жизнедеятельности. Структура менеджмента в значительной степени, почти зеркально, отражает сущностные характеристики объекта управления. Степень влияния обратных связей также играет важную роль. Действующая модель управления сложилась как функция совокупности реализации проектной документации и деятельности населения по обустройству жизненного пространства.

Культура неоднородна. В обществе сосуществуют разные культурные стереотипы, отражающие разницу в менталитете групп и сообществ. При этом основная часть населения, сформировавшаяся в системе культурных и пространственных особенностей «места», всегда достаточно консервативна.

Отдельные группы, сложившиеся из иногороднего и сельского населения, прибывшие в данное место на постоянное жительство, являются носителями иной, иногда кардинально отли- 
чающейся, культуры и в зависимости от степени ассимиляции могут оказать воздействие на систему управленческих решений, структуру управления и проектные решения. Аналогичная ситуация возникает и с относительно немногочисленной, но влиятельной группой граждан, представляющих культурную элиту. Специфика менталитета этой группы определяется повышенной креативностью и склонностью к внедрению нового, поскольку характерное для этой части жителей той или иной территории творческое мышление всегда нацелено на выход за пределы известного, существующего, т. е. на инновации. Культурная элита всегда пользуется большим влиянием на управленческую структуру.

В целом вектор принимаемых решений складывается под воздействием культурных предпочтений разных групп населения, тренда градостроительной политики, проектной градостроительной документации, действующих нормативных и правовых актов. Качество управления городским развитием также во многом зависит от интеллектуального уровня и креативности кадрового состава городских менеджеров. При этом очевидно, что подбор персонала для управленческого аппарата осуществляется чаще всего по другим критериям.

Таким образом, гарантией появления инновационных решений муниципального управления, направленных на позитивное развитие города, служит устойчивость системы, обеспечивающей эффрективное сотрудничество городского менеджмента с интеллектуальными лидерами креативных групп и профессиональных сообществ. Немалое значение здесь имеет организация перманентной структуры дополнительного образования и регулярной аттестации кадрового состава служб муниципального управления, в особенности руководящего звена.

Анализ успешной практики управления городским развитием за последние десятилетия показывает, что в основе каждого подобного примера лежат идеи, формирование и реализация которых были невозможны без опоры на интеллектуальный потенциал населения и требовали серьезных интеллектуальных усилий и высокого уровня креативности [1, с. 35]. Очень часто в подобных случаях фигурируют модели управления, демонстрирующие связку уполномоченных органов муниципального управления с городскими активистами, бизнес-структурами, профессиональными консалтинговыми бюро или общественными организациями, т. е. добавочным «подключенным интеллектом». Положительные примеры воплощения инновационных идей городского развития иллюстрируют, как эффективная реализация стала возможной благодаря трансформации привычных управленческих моделей или полной их смене.

Сегодня система муниципального управления серьезно страдает «кадровым голодом», выражающимся в дефиците высококвалифицированных специалистов почти во всех секторах городского развития. Речь идет о профессионалах, не только сведущих в вопросах ежедневного содержания отраслей городского хозяйства, но и хорошо представляющих контуры позитивного будущего своей отрасли. Причем сама система чаще всего не осознает этой проблемы, удовлетворяясь относительно успешными решениями повседневности. Преодоление данного препятствия требует существенных рефлекторных усилий для осознания необходимости вовлечения в структуру муниципального менеджмента серьезных интеллектуальных ресурсов. Только добросовестное выполнение рутинных обязанностей, как правило, не обеспечивает устойчивого и конкурентоспособного развития.

С эволюцией человека интеллект становится специфической высокой формой сознания. Его развитие обусловлено двумя фракторами: внутренним - механизмом строения нервных клеток человеческого мозга и внешним - традициями культуры и общества. На этапах истории интеллект постепенно превращался в рабочий инструмент человечества.

Однако средний уровень развития интеллекта не смог бы привести к тому прогрессу науки и искусства, который мы имеем сегодня. Степень умственного развития разных личностей всегда различна. Высшую его ступень называют интеллектуальностью, а людей, обладающей ею, - интеллектуалами. Интеллектуал - это человек - генератор прогрессивных идей, обладатель обширных знаний, разнообразных интересов и большого кругозора. «Эти качества интеллектуалов во многом стимулировали развитие общества в целом» [2, с. 46].

Интеллектуальность - база креативности, сознательного творчества человека, направленного на формирование и реализацию идей развития. Оценивая роль интеллекта и креативности в совершенствовании муниципалитета, Ч. Лэндри пишет: «Главным жизненно важным ресурсом города являются люди. Человеческий ум, желание, мотивы, воображение и творческие способности все чаще рассматриваются как стратегический резерв развития городов, который вытесняет на задний план такие их достоинства, как местоположение, природные ископаемые и доступ к рынку. Творческий потенциал тех, кто живет в городах и управляет ими, определяет их будущий успех» [3, с. 15].

Эффрективные управленческие решения во многом зависят от полноты информации, которой обладает субъект управления. Один из важнейших способов исследования территории, поз- 
воляющих регулярно пополнять и актуализировать информационную базу, - системно организованный мониторинг управляемого объекта (местности). Существует достаточно много методов организации мониторинга территории.

В данном случае речь идет не только о текущем (стационарном) состоянии местности. В соответствии с синергетическим подходом должен осуществляться маркетинг изменений, происходящих на территории вследствие принимаемых управленческих решений. Для этого в рамках мониторинговых исследований необходимо организовать обратную связь с жителями изучаемой территории. Один из наиболее эффрективных инструментов обратной связи - контент-маркетинг. Поселений «может стать инновационным элементом маркетинговых инструментов. А маркетолог должен стремиться к инновациям» [4, с. 76].

Маркетинговый подход позволяет получить дополнительный инновационный эффект помимо сбора статистической информации. Это эффрект живого отклика социума на управленческие решения. Использование контент-маркетинга дает возможность постоянно расширять круг приверженцев решений, обеспечивать лояльность граждан к реализуемым мероприятиям. Воронка контент-маркетинга применительно к сфере услуг адекватна воронке аттрактора в синергетике и коррелирует с методом партисипации (соучастия).

Под партисипацией понимается более широкое участие потребителя в процессе проектирования [5, р. 392]. «Информация о происходящем в городе, которую распространяют СМИ, для его жителей приобретает значимость общественного блага» [6, с. 74]. По оценкам, лишь 10-15\% людей относятся к сознательным потребителям новостей: они думают, действуют рационально и понимают всю выгоду информированности. Сам феномен распространения информации заинтересовал экономистов лишь в конце 70-х - начале 80-х гг. XX в., и политическая экономика прессы стала важной частью экономической науки» [7, с. 96].

Асимметрия информации - «продавцы» и «покупатели» в разной степени владеют информацией о товаре. Поведенческая (бихевиористская) экономика - люди склонны к нерациональному поведению, представляющему собой не патологию, а норму. Теория асимметричной информации и поведенческая экономика позволили объяснить роль СМИ в поведении людей.

Местные средства массовой информации, инфрормируя потребителя (население) о происходящем в городе, услугах и продукции местного бизнеса, ориентируют в направлениях и подстегивают развитие малого и среднего бизнеса. Сообщая гражданам о программах развития территории, СМИ во многом предопределяют вектор динамики деловой активности, формируют отношение к градостроительным инициативам муниципального управления.

Для средств массовой информации реклама особенно важна как средство существования. Рекламодатели появляются с развитием предпринимательства, ориентируясь больше всего на местных потребителей. Таким образом, СМИ подстегивают развитие малого бизнеса. Рекламодателям важно, чтобы о них узнала не вся страна, а прежде всего жители тех мест, где у них есть точки продаж. Это заставляет местные СМИ сосредоточиваться на таргетированной (адресной) рекламе [8, с. 78]. Таргетирование рекламы важно для местного бизнеса, глобальным корпорациям это не нужно, ведь их продукция и так продается по всему миру. Таргетирование новостей эффективно осуществлять через интернет-каналы. Успешно функционируют информационные платформы об обустройстве города, например «ДомДворДороги» (Москва).

Сегодня в муниципальной практике Российской Федерации информационный ресурс сильно недооценивается и развивается медленно, в основном в мегаполисах. Как правило, действие пресс-центров муниципалитетов сводится к распространению текущей информации, редко используются специальные методы сценарного планирования воздействия на социальную среду города.

Еще хуже обстоит дело с обратной связью: в муниципалитетах практически отсутствуют специальные службы, консалтинговые или аналитические бюро, отслеживающие и анализирующие новостные каналы в целях корректировки социально-экономической и градостроительной политики, местного управления. Создание подобных служб является одной из важнейших управленческих задач при реализации проектов градостроительного развития территории.

\section{Ссылки:}

1. Лэндри Ч. Креативный город. М., 2006. 399 с

2. Толеховский В. Развитие западного интеллектуализма. М., 2007. 234 с.

3. Лэндри Ч. Указ. соч. С. 15.

4. Роуз Р., Пулицци Дж. Управление контент-маркетингом. Практическое руководство по созданию лояльной аудитории для вашего бизнеса. М., 2000. 240 с.

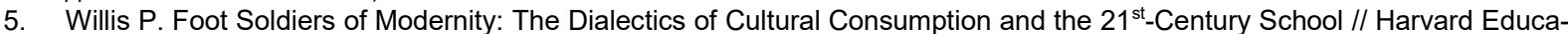
tional Review. 2003. Vol. 73, no. 3. P. 390-415. https://doi.org/10.17763/haer.73.3.0w5086336u305184.

6. Стимулы, парадоксы, провалы: город глазами экономистов. М., 2015. 224 с.

7. Там же. С. 96.

8. Маркетинг : учебник / под ред. В.В. Герасименко. 3-е изд. М., 2015. 489 с. 


\section{References:}

Gerasimenko, VV (ed.) 2015, Marketing, textbook, 3rd ed., Moscow, 489 p., (in Russian).

Incentives, paradoxes, failures: the city through the viewpoint of economists 2015, Moscow, 224 p., (in Russian).

Landry, Ch 2006, Creative city, Moscow, 399 p., (in Russian).

Rose, R \& Pulizzi, J 2000, Managing content marketing. The real-world guide for creating passionate subscribers to your brand, Moscow, 240 p., (in Russian).

Tolekhovsky, V 2007, Western intellectualism development, Moscow, 234 p., (in Russian).

Willis, P 2003, 'Foot Soldiers of Modernity: The Dialectics of Cultural Consumption and the 21st-Century School', Harvard Educational Review, vol. 73, no. 3, pp. 390-415. https://doi.org/10.17763/haer.73.3.0w5086336u305184. 